\title{
Analysis of the Pipelines Functional Safety on the Mining Areas
}

\author{
Barbara Kliszczewicz ${ }^{1}$ \\ ${ }^{1}$ Department of Geotechnics and Roads, Civil Engineering Faculty, Silesian University of Technology, 44-100 Gliwice, Akademicka 5, \\ Poland \\ *Corresponding author, e-mail: barbara.kliszczewicz@polsl.pl
}

Received: 25 May 2021, Accepted: 01 July 2021, Published online: 19 July 2021

\begin{abstract}
Buried pipeline systems, which transports water, sewage, oil or gas, perform the substantial role in urban areas. Sometimes their safe functioning is hampered because of damages caused in mining areas. In this article a characterization of the influence of mining activities on underground pipelines was presented. A description and classification of damages to pipelines with reference to mining influences were given of the various different pipelines systems and pipes materials. An illustrative example of damages to the stoneware sewage pipeline located on the mining area was presented. The effort of such pipe was carried out with using numerical methods (FEM). Model 2D represented stoneware pipe - soil system influenced by traffic load (SLW60) and the mining ground deformations (horizontal strains increasing from 0 to $9 \mathrm{~mm} / \mathrm{m}$ ). Model was built in ZSoil.PC program. The numerical analysis was performed as incremental and iterative. On the basis of the obtained results of numerical analysis (internal forces) the safety factors for various pipes classes with different bending strength were determined. Moreover, functional safety of the spigot-andsocked joints subjected mining impact was also assessed. During increasing of mining impact the insertion length at joints should provide free movement of spigots inside the socket, without losing the join tightness. It has been shown that the insertion length at analyzed stoneware pipes joints wasn't appropriate which may result in damage of the spigot-and-socked joints during increasing the mining ground deformations.
\end{abstract}

Keywords

pipeline's damages, mining area, numerical analysis (FEM), safety factor, spigot-and-socked joints

\section{Introduction}

The construction of modern pipelines transporting water, oil, gas or wastewater has been increasingly associated with the necessity to run them through heavily urbanized areas or the so-called "difficult" areas with impacts having a degrading effect on pipes. Such areas include those subject to mining influence. Some of these impacts are difficult to foresee because of various uncertainties regarding hazards and the loadings applied on pipelines in these area and pipelines' changing resistance over time. Therefore, it was mostly difficult to include them in the process of designing pipelines and to develop an effective protection concept. Significant improvement has been made in understanding of these effects and uncertainties during the last decades. In addition, there have been improvements in the pipe materials and their mechanical properties. Nevertheless, the situation is serious in the case of the existing pipelines, which are sometimes made of materials with relatively low load-carrying capacity and are technically worn out. These uncertainties require application of holistic approaches which take into account loadings coming from extreme events on the pipelines and pipeline behavior.

This article focuses on the problem of pipelines located in mining areas, analyzing and classifying damage recorded due to the occurrence of additional, degrading impacts.

\section{Characteristic of the mining and seismic areas}

Mining areas include those affected by past and current underground mining of useful minerals, including mainly hard coal or copper. Changes occurring in the rock mass and on the ground surface, resulting from mining works, causes damage to civil structures located in the area of the mining impacts. These phenomena concern both enclosed structures, including compact technical infrastructure facilities, as well as linear structures, which include underground service infrastructure. A visible effect of the degrading impact of underground mining operations is, among others, an increased failure rate of pipelines [1]. 
The extent and nature of changes occurring in the rock mass and on the ground surface depend on the size of the mined out field and its depth as well as on the mining system and the speed of mining. The geological nature of strata of overburden and its tectonics, water accumulation in the rock mass as well as the history and remains of previously performed mining works are also important.

The process of changes in the rock mass caused by mining operations extends from the post-mining void towards the surface. The effects of movement of rock mass elements are visible on the ground surface in the form of extensive or local deformations. As a result of deep mining operations, with a less rigid overburden, the deformation is more extensive and mild (continuous deformations in the form of subsidence basins). The result of shallow mining operations and mining operations carried out in the area of tectonic faults is local damage to the land surface (discontinuous deformations). They may be linear (ditches, cracks, terrain thresholds) or compact (depressions, hoppers) and their course is usually quick and not preceded by any signs. Land deformations occurring as a result of underground mining operations are often accompanied by changes in water conditions, consisting in lowering of the water table (drying of a part of the area) or its rise (formation of non-drained floodplains). Water movement also generates additional surface deformations. In many areas within the range of mining impacts, rock mass shocks (the so-called induced mining seismic activity) causing ground vibrations are also recorded. Their nature can be compared to earthquakes, but their intensity is significantly smaller. The listed phenomena are described extensively in literature concerning construction in mining areas [2-3].

Continuous deformations, in a form of subsidence basins, being the effect of mining works are characterized by five parameters: vertical displacements $w(x)$, curvatures $K(x)$, horizontal strain $\varepsilon(x)$ as well as horizontal displacements $u(x)$ and inclinations $T(x)$.These parameters can be calculated, for example, according to BudrykKnothe theory [4]. The first three of them are considered particularly important for buried pipelines, as they affect the change of vertical alignment and loads of such pipelines in the longitudinal and transverse directions [5-6]. On the other hand, discontinuous deformations (in a form of collapses, thresholds, crevices etc.), which are difficult to predict, may change the conditions of pipelines support and, consequently, may result in a change of their static diagram and in an additional strain. The impact of mining tremors on underground pipelines is the most difficult to estimate. However, based on the observations made so far, this impact can be considered to be particularly dangerous for rigid and technically worn pipelines [7].

Mining impact performance of pipelines depends on various factors of which the primary ones are pipe material, joint type, pipe coating and trench properties, intensity of shaking, and the properties and characteristics of ground displacements around the pipeline. Most of the pipelines are buried in the ground and therefore soil-pipeline interaction becomes important as mining actions transferred and applied to pipelines via soil around the pipelines.

The resistance of the pipeline against the mining loading stem from pipe material and joint properties. In order to be on the safe side, the resistance of the pipelines should be higher than the loading with a certain margin of safety.

According to joint type, pipelines can be considered as continuous or segmented pipelines. Mining behavior of continuous and segmented pipelines differ significantly and should be evaluated separately. For example, welded steel pipelines mostly used in gas and petroleum transmission or PE pipelines are considered as continuous pipelines because their strength and deformation characteristics are almost similar to those of the material it is made of. However, the ductile iron pipelines used in water transmission systems are segmented and can be separated at joints when exposed to extensional strains during the mining impact. In the case of mining, the appropriate insertion length at pipeline's joints is essential. During revealing mining, appropriate insertion length at joints allow free movement of spigots inside the socket, without losing the join tightness. Such solutions provide pipelines more flexibility and make them better tolerate mining or seismicity induced soil deformations.

Certainly, mining impacts are one of many causes of damage. Other causes include aggressive impact of ground water and soil, low quality of built-in materials as well as material, design and workmanship defects or the impact of excessive static and dynamic loads.

Strength analyzes of the pipelines with consideration of the mining impacts can be conducted with using classical analytical method or by applying numerical method. In the latter case the pipelines - soil system $(2 \mathrm{D}$ or $3 \mathrm{D}$ models) is using [8-10]. The soil behavior can be simulated by means of a wide range of constitutive models - from the most commonly used elastic-ideally-plastic Coulomb-Mohr model (CM) to more advanced models, e.g., the elastic-plastic model Hardening Soil Small (HSS) with isotropic hardening [11]. 


\section{Classification of the pipeline's damages and their causes}

Damages to pipelines in both mining and service areas are recorded and documented by services managing respective networks. One of the main difference in terms of the repairing and restoring the system comes from the cost point of view. The owner of the utilities are primarily responsible from the repair costs whereas the costs of pipeline repair is covered by the mining company provided that a cause and effect relationship is established between damage and mining works [12]. The identification of damages to the pipelines are made by the crew of the utility companies responsible from the system. It is critical that important information about the damages should be recorded as completely as possible. Because these damages provide valuable information about the failure mechanisms of the pipelines and helps understanding the behavior of pipelines in seismic or mining areas. As a result, much better planning and mitigation strategies can be prepared to reduce future damages.

The assessment of the degree of the destructive impact of mining operations on pipelines should be carried out taking into account documented non-compliance of continuous deformation forecasts with the actual deformation (in the scope of parameters of the mining area and directions of their occurrence), finding of discontinuous deformations in the place of failure or damage and recorded, significant paraseismic impacts (mining tremor). The observed damages to pipelines caused by mining impacts in relation to the type of network and the material solution are classified below:

- water supply networks:

steel pipelines: longitudinal and transverse cracking, fitting cracking, pipeline collapsing, damage to joints (welding cracking, coming out of the plain end from the expansion joint, damage to the flange connection),

cast iron pipelines: pipeline cracking and collapsing, damage to joints (coming out of the plain end or the sealing from the socket, damage to the flange connection),

plastic pipelines: cracking, damage to pipeline joints (butt weld cracking, coming out of the plain end or the sealing from the socket),

fittings: cracking of the gate valve body, broken connection of the hydrant body with the pipeline.

- sewerage networks:

concrete and reinforced concrete ducts: longitudinal and transverse cracking, duct collapsing, loss of tightness of connections, damage to manholes, functional disturbances (reduction or increase of slopes, non-drain sections), stoneware pipe: scratches, circumferential and longitudinal cracking, local tube wall losses, damage to spigotand-socket pipe connections, displacements and mechanical damage to sealing rings, functional disturbances (reduction or increase of slopes, non-drain sections),

plastic ducts: damage to joints (welding cracking, coming out of the plain end or the sealing from the socket),

sewer manholes (concrete, reinforced concrete, plastic): (damage to the pit and walls of the manhole, damage to the roadway in the area of the manhole),

- gas networks:

steel pipelines: longitudinal and transverse cracking, pipeline collapsing, damage to joints (welding cracking, coming out of the plain end from the expansion joint and loss of its tightness, damage to the flange connection),

cast iron pipelines: joint damage,

plastic pipelines: pipe cracking, damage to pipeline joints (cracking of the butt weld, loss of tightness of the electrofusion joint),

fittings: cracking of the gate valve body or the valve,

- district heating systems:

steel pipelines routed in ducts or above the ground: pipeline displacements and falling out of sliding supports, longitudinal or transverse cracking of the pipeline and its collapsing, damage to joints (weld cracking, damage to expansion joints),

pre-insulated pipelines: pipeline displacements in the ground, longitudinal or transverse cracking, pipeline collapsing, damage to joints (welding cracking, damage to expansion joints),

district heating ducts: disturbances in duct slopes and damage to their structures.

\section{The example of rigid pipes damage on the mining area} All information materials concerning the described example of damage to the sewage system have been made available for publication by the system owner (Municipal Engineering Department of one of the cities in Poland, particulars of location are reserved). The gravity sewerage located within the access road to the domestic premises was analyzed. This system consists of four parallel ducts with various length, jointed in the common duct (Fig. 1 - sign 01, 02, 03 and 04). The channels are built of stoneware pipes size DN200 with polymer concrete manholes Ø1000/D400. The segments of the stoneware pipes, with spigot-and-socked joints, are $2.5 \mathrm{~m}$ in length. Average depth of the socket is $70 \mathrm{~mm} \pm 15 \mathrm{~mm}$. The pipe spigots should be inserted to sockets ensuring appropriate distance ( $\max 20 \mathrm{~mm})$. 
The sewer system was built on the mining area. The land deformations caused by underground mining became apparent in the form of a subsidence basin, with a maximum subsidence of about $2.1 \mathrm{~m}$. Both value and the direction of the horizontal strains $\varepsilon(x)$ of this influence were variable. In the zone of small subsidence (up to ca. $0.7 \mathrm{~m}$ ) the value of the horizontal strains were included in a range from +1.5 to $+4.0 \mathrm{~mm} / \mathrm{m}$ and they were tensile in character. In the zones where subsidence were larger, the character of the horizontal strains changed to compression and the extreme values of up to $-6.0 \mathrm{~mm} / \mathrm{m}$ were reached, locally achieving $-9.0 \mathrm{~mm} / \mathrm{m}$. Maps of the subsidence and the horizontal strains isolines within the gravity sewerage system are presented in Fig. 1 and Fig. 2.

The gravity sewerage was repeatedly subjected to dynamic influences connected with mining tremors. The intensity of tremors was diverse, with the maximum energy of $4 * 108 \mathrm{~J}$ achieved.

Damages, which with different intensity appeared on all segments of gravity sewage, were inventoried with the use of inspection CCTV equipment. Part of those damages

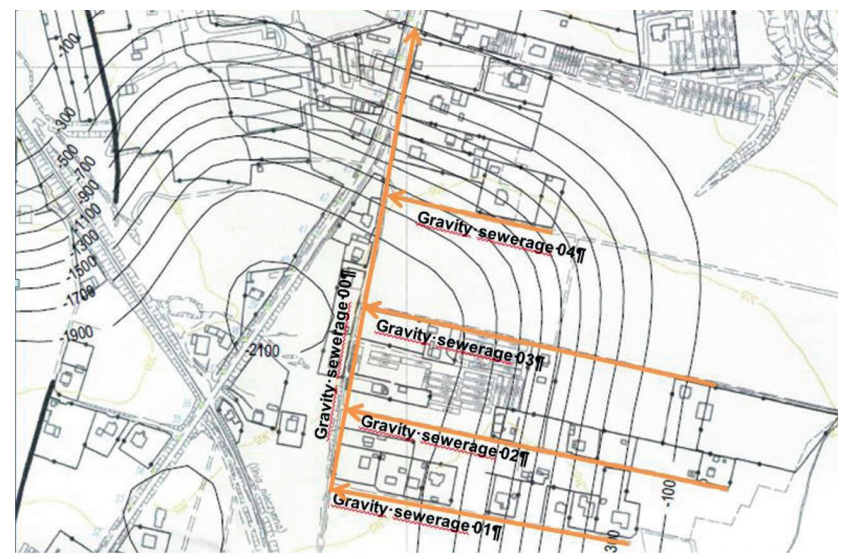

Fig. 1 Scheme of gravity sewerage on the background of map of the subsidence isolines $w(x)$

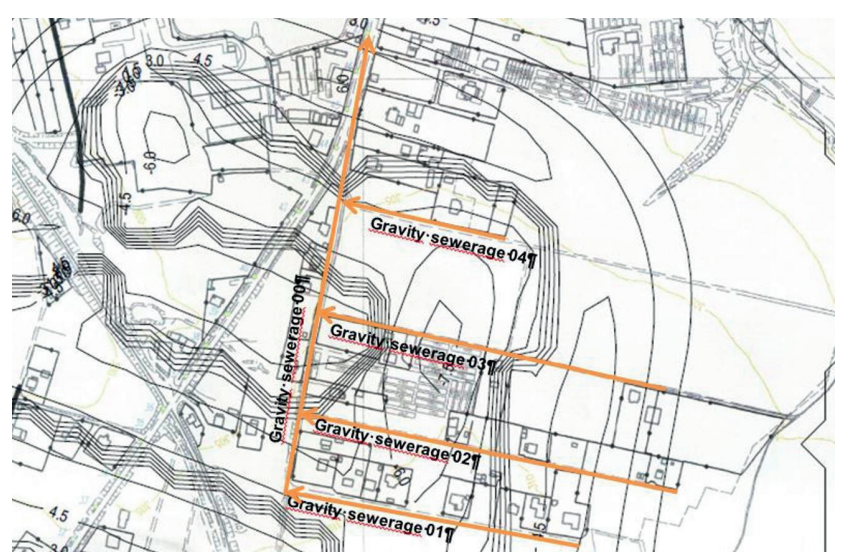

Fig. 2 Scheme of gravity sewerage on the background of map of the horizontal strains isolines $e(x)$ had typically mechanical character and was associated with the fact of exceeding of the material durability for the pipes. To distinguish between two most typical cases the circumferential and longitudinal cracking and local shrinkages in pipe's walls were identified (Figs. 3 and 4).

The next type of the damage to gravity sewerage was distinguished within joints of pipes. They were connected with damage to spigot-and-socked joints of pipes and mechanical failures of gasket rings as well (Fig. 5).

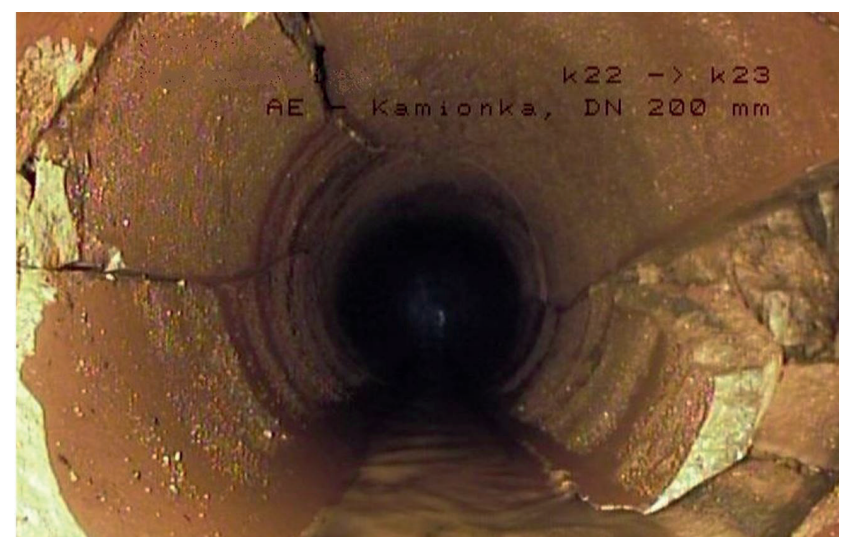

Fig. 3 Damage to the pipe - longitudinal and transverse cracking and local wall shrinkage

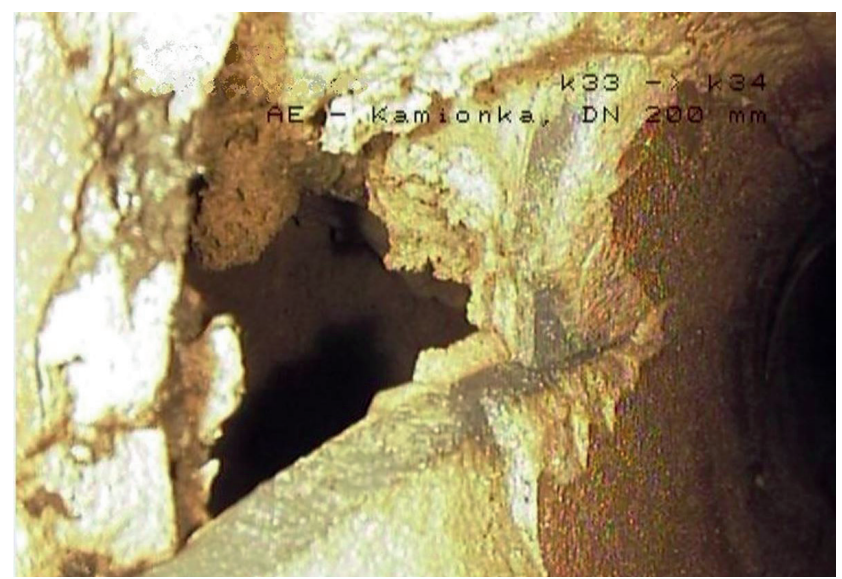

Fig. 4 Damage to the pipes - local wall shrinkage

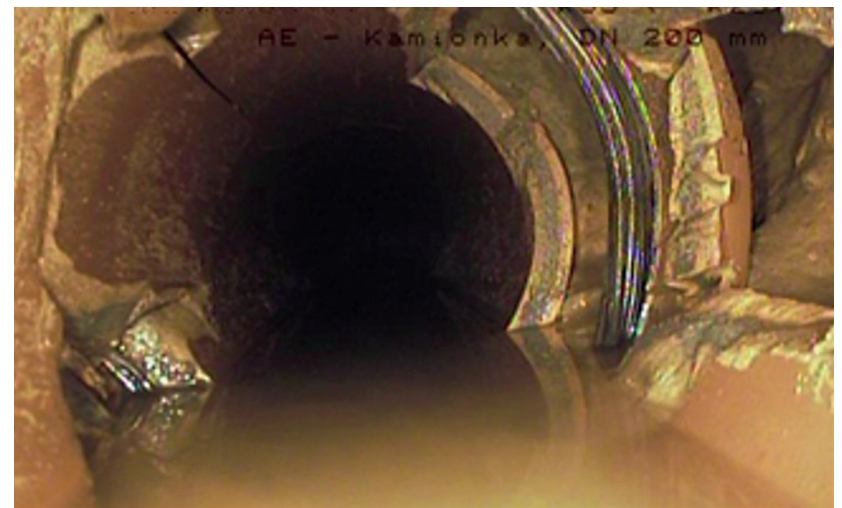

Fig. 5 Damage to spigot-and-socket joint 
Changes of inclination in ducts and occurrence of local contra-inclinations were the third kind of damage to the gravity sewer system.

These changes were caused by uneven subsidence of land. Consequently it disturbed gravity flow of the sewage in part of the ducts (Fig. 6). Furthermore, on most of the segments of the gravity sewerage the infiltration of groundwater was noted.

The damages presented above are related both to exceeding of strength parameters of the pipe's material and the compensation capacity of the spigot-and-socked joints. Due to the different pipelines location in relation to the directions of mining, the impact of underground mining on the pipelines damage was assessed using numerical FEM analysis (simulation of the compressive horizontal strains $\varepsilon(x)$ operating on the pipe cross-section) and kinematic analysis (motion of the spigot in the joint during the increase soil deformation).

\section{Numerical analysis of the stoneware pipes - soil system with consideration of mining influence}

Numerical FEM model representing a buried stoneware pipe of a unit length in a plane strain condition was implemented within the ZSoil.PC program. Model represented detached rectangular area of the native soil in which the pipe was laid by use of the trench method (Fig. 7). The geometric dimensions of both models are the same and lists accordingly: the total depth $H=3.95 \mathrm{~m}$ and total width $L=3.00 \mathrm{~m}$, the thickness of the soil layer above pipe $h=2.7 \mathrm{~m}$, width of the trench $b=1.2 \mathrm{~m}$. The external pipe diameter is $D_{e}=242 \pm 5 \mathrm{~mm}$, the wall thickness of $s=0.021 \mathrm{~m}$. The numerical calculation of models were conducted taking into consideration different material zones (native soil, backfill) described by means of the CM model. The parameters of the CM model are summarized

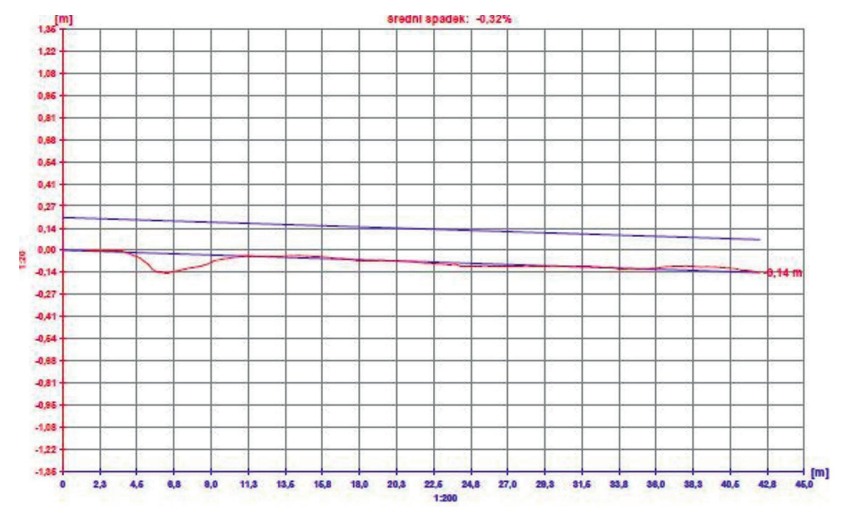

Fig. 6 The example of the duct's inclination profile with local change (contra-inclination) in Table 1 and their arrangement in the numerical model shown in Fig. 7. The stoneware pipe material was modelled as linear elastic with the Young modulus $E=55000 \mathrm{MPa}$, bulk weight $\gamma=22.0 \mathrm{kN} / \mathrm{m}^{3}$, Poisson ratio $n=0.2$.

The traffic load (SLW60) was represented by corresponding uniformly distributed load on top of the model $(t=0$ to $t=5)$. The operations of the mining deformation (compressive horizontal strains $\varepsilon(x)$ ), increasing from $0 \mathrm{~mm} / \mathrm{m}$ up to $9.0 \mathrm{~mm} / \mathrm{m}(t=5$ to $t=185)$ was simulated by applying appropriate values of displacements in supports at external edges of the model. The analysis was provided as incremental and iterative.

As a result of action of ground weight and traffic loads $(t=5)$, vertical stresses in the ground above the rigid, stoneware pipe are concentrated (Fig. 8(a) and Fig. 8(b)). The value of the concentration factor, calculated as the ratio of vertical stresses above the pipe to their value near the vertical edge of the model, is 1.57. These conditions change (Fig. 8(c) and Fig. 8(d)) while the compressive horizontal strains $\varepsilon(x)$ are increased. The distribution of both vertical and horizontal stresses in the soil during action of all loads and mining impact in points surrounding main pipe ( $t=0$ to $t=185$ ) is shown in Fig. 9.

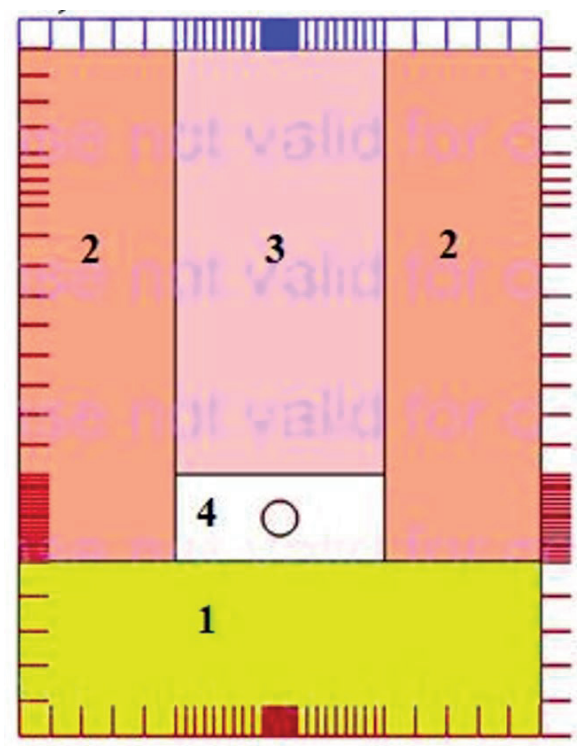

Fig. 7 Stoneware pipe - soil model

Table 1 Material parameters of native soil and backfills

\begin{tabular}{lccccc}
\hline \multirow{2}{*}{ Parameter } & \multirow{2}{*}{ Unit } & \multicolumn{2}{c}{ Native soil } & \multicolumn{2}{c}{ Backfill } \\
& & 1 & 2 & 3 & 4 \\
\hline Young modulus & {$[\mathrm{MPa}]$} & 160 & 16 & 20 & 16 \\
Friction angle & {$\left[{ }^{\circ}\right]$} & 30 & 35 & 45 & 20 \\
Cohesion & {$[\mathrm{kN} / \mathrm{m} 2]$} & 20 & 10 & 20 & 10 \\
Unit weight & {$[\mathrm{kN} / \mathrm{m} 3]$} & 20 & 20 & 20 & 20 \\
\hline
\end{tabular}



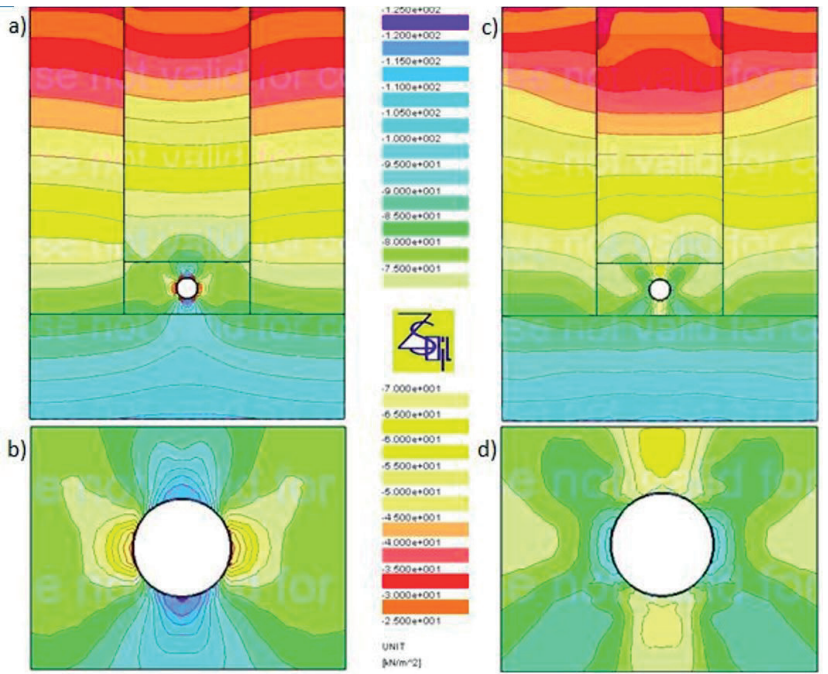

Fig. 8 Maps of vertical stress in soil: a) acting of the traffic load ( $(=5)$; b) enlarging pipe surroundings ( $t=5)$; c) acting of the traffic load and compressive horizontal strains $\varepsilon(x)(t=185)$; d) enlarging pipe surroundings $(t=185)$

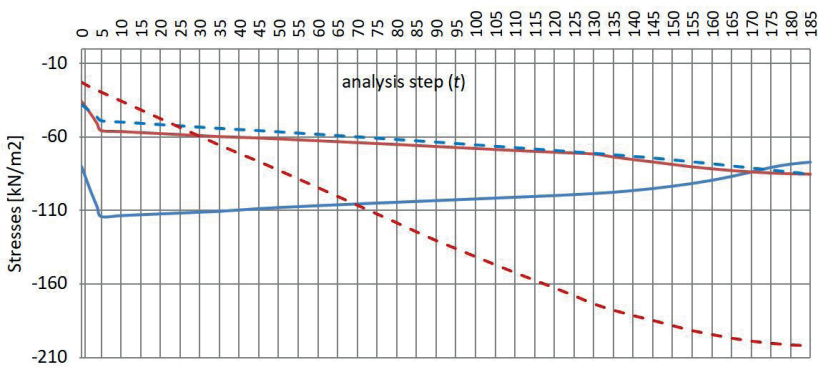

$$
\begin{array}{ll}
- \text { Stress-YY - crown } & - \text { Stress-YY - springline } \\
--- \text { Stress- } X X \text { - crown } & --- \text { Stress-XX - springline }
\end{array}
$$

Fig. 9 The distribution of vertical (YY) and horizontal (XX) stresses in the soil due to action of all loads and mining impact in points surrounding pipe's crown and springline (from $t=0$ to $t=185$ )

As a consequence of these processes the internal forces (circumferential bending moments $M_{z}$ and circumferential normal forces $N_{x}$ ) also changes (Fig. 10).

The stoneware pipes are produced in different classes, for which the bending strength varies within a range of 10-20 MPa. For all classes the same minimum value of the safety factor $F=2.2$ is adopted. In the bending strength range and different loads ("non-mining" and "mining") the values of the safety factor $F$ were determined (Fig. 11). The values $F$ were determined taking into account the stresses in the pipe wall at its main points (crown, springline, invert).

Based on the analysis of this diagram, the following can be stated:

- for analyzed stoneware pipe the "non-mining" loads (ground weight and traffic load) are quite safe for all pipe classes $(F>2.2)$,

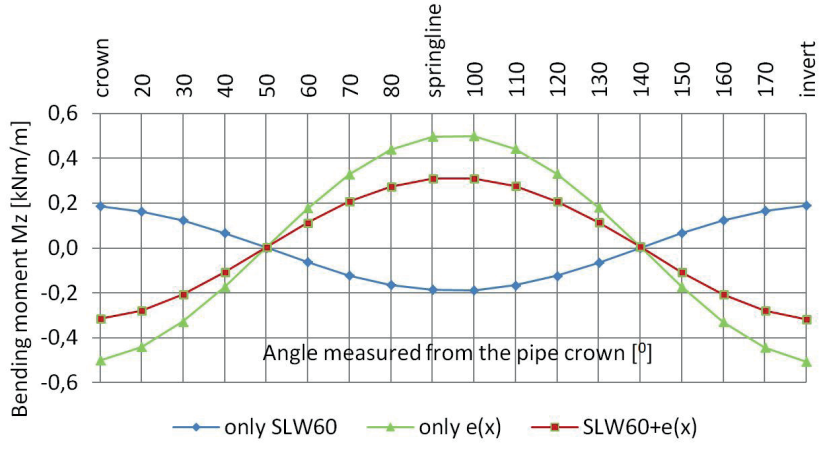

(a)

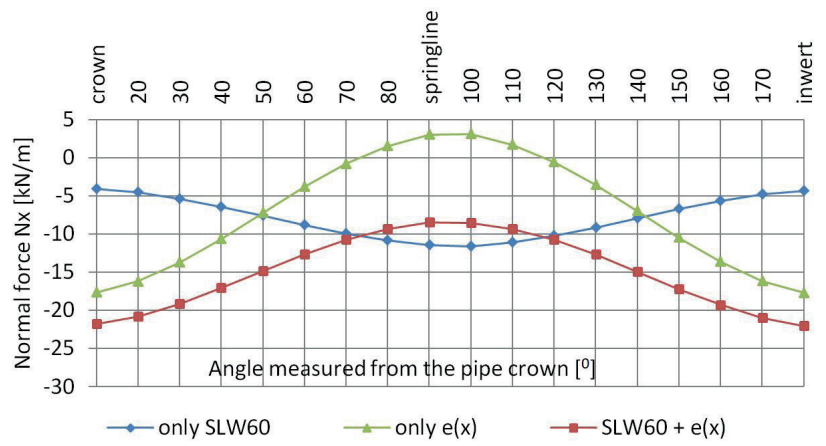

(b)

Fig. 10 Diagrams of the internal forces: a) bending moments $M_{z}$; b) normal forces $N_{x}$

- the value of safety factor $F$ decreases as the "mining" loads i.e. influence of compression horizontal ground deformation $e(x)$ increase,

- in case of traffic load and influence of compressive horizontal strains $\varepsilon(x)$, marked as SLW60 $+e(x)$ on the Fig. 11, for lower class of pipe (bending stress $<$ 14.0 MPa) the safety factor $F<2.2$,

- a particularly dangerous situation occurs when there is no vertical load, marked as only $e(x)$ in the Fig. 11. Then only for pipes with bending stress over $18 \mathrm{MPa}$ value of safety factor $F>2.2$ is maintained.

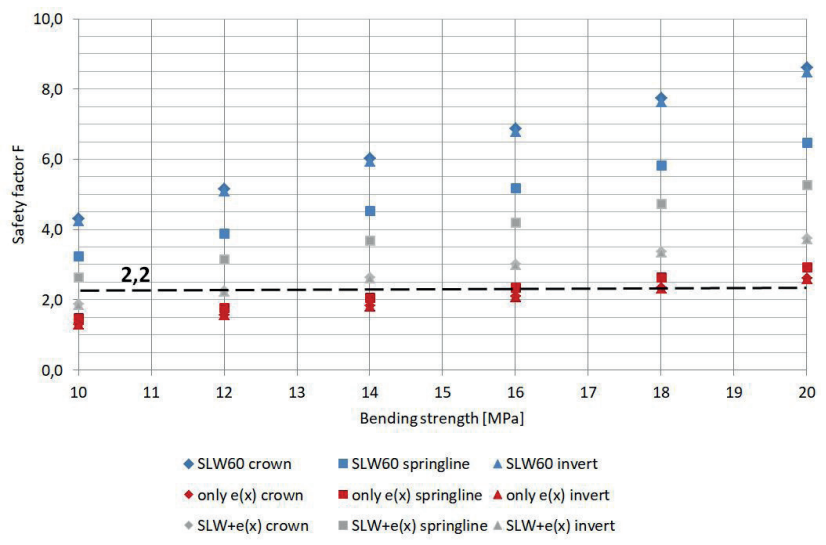

Fig. 11 Diagrams of the values of safety factor for different classes of pipes and different loads 
Based on the results of the numerical analysis, it can be concluded that the operation of the compressive horizontal strains $\varepsilon(x)$ has a degrading effect on stoneware pipes. This applies especially to pipes with lower material parameters and in case of intensive mining impact.

\section{Assessment of the spigot-and-socked joints functioning}

Mining ground deformation in the longitudinal direction to the pipeline axis causes pipes displacements, which should be compensated in the joints. Ensuring unhampered mutual movement of the spigot in the socked, related to thinning or compression of ground during mining deformation, determines tightness and reliability of joints.

Analyzed stoneware pipes are produced in segments of $l=2.5 \mathrm{~m}$ in length, with spigot-and-socked joints. The standard socked depth is $l_{1}=70 \mathrm{~mm} \pm 15 \mathrm{~mm}$, insertion depth of the spigot into the socked $l_{2}=50 \mathrm{~mm}$, spigot depth reserve $l_{3}=20 \mathrm{~mm}$, pipe alignment tolerance during assembly is $3 \mathrm{~mm}$, reserve for the gasket assembly $30 \mathrm{~mm}$. Described pipe joint is shown schematically in Fig. 12.

Taking into account tolerance of socked depth (-15 mm), insertion depth of the spigot into the socked $(50 \mathrm{~mm})$ and tolerance of pipe assembly $(3 \mathrm{~mm})$ the reserve of spigot depth $l_{3}$ (distance between pipes) is reduced to only $2 \mathrm{~mm}$ $(55-50-3=2 \mathrm{~mm})$. Such small distance exposes socked joint to damage (cracking) caused by compressive horizontal strains of ground. Minimal distance between pipes inside socket joint and minimum socked depth for different values of horizontal strains of ground are listed in Table 2.

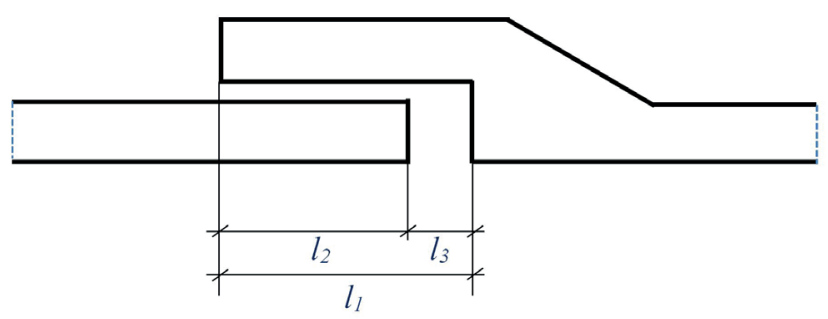

Fig. 12 Diagram of spigot-and-socked joint of stoneware pipes
As can be seen, in such situation the destruction of the socked can be avoided for horizontal strains of ground equal $1.5 \mathrm{~mm} / \mathrm{m}$ when depth of insertion spigot to socked does not exceed $43 \mathrm{~mm}(55-43-3=9 \mathrm{~mm}<10 \mathrm{~mm})$.

Based on the above analysis, it can be concluded that the damage described in point 4 (e.g., see Fig. 5) is related to action of horizontal strains of ground, which cause relative displacement of the pipe segments inside the joints. In the case of compressive horizontal strains the pipe segments are pressed against each other. Character of damages indicated that depth of the socket was too small and probably distances for segments inside joints were not properly applied.

\section{Conclusions}

Underground mining exploration causes a number of unfavorable changes in the subsurface layer of the ground. As a result, the conditions for the foundation of building structures, including underground pipelines, are subject to change. Main mining impacts (vertical displacements, curvatures, horizontal strain, inclinations) cause changes in the pipelines and results in additional loads. In case of the pipelines that are not adapted to withstand additional impacts and loads, or pipelines that are technically worn, their damage should be taken into account. The extent and nature of the damage depends on many factors such as pipe material, joint type, pipe coating and trench properties, intensity of tremors, and the properties and characteristics of ground displacements around the pipeline.

The article presents the classification of the observed typical damage of pipelines in the context of various types of networks and use of different material. The case of a stoneware sewage pipeline located in the mining area was specifically considered. The nature of the damages of these pipelines, recorded by CCTV inspection, indicated that the pipeline was not adapted to withstand mining influence. The cause-and-effect relationship between the damage and the conducted underground mining

Table 2 The minimal distance between pipes inside socket joint

\begin{tabular}{lccc}
\hline $\begin{array}{l}\text { Values of horizontal strains } \\
{[\mathrm{mm} / \mathrm{m}]}\end{array}$ & $\begin{array}{c}\text { Spigot displacement } \\
(\mathrm{mm})\end{array}$ & $\begin{array}{c}\text { Minimal distance between pipes } \\
(\mathrm{mm}) *\end{array}$ & $\begin{array}{c}\text { Minimum socket depth } \\
(\mathrm{mm}) * *\end{array}$ \\
\hline 0.3 & $2.5 \times 0.3=0.75$ & 10 & $2 \times 5+30=40$ \\
1.5 & $2.5 \times 1.5=3.75$ & 18 & $2 \times 10+30=50$ \\
3.0 & $2.5 \times 3.0=7.50$ & 32 & $2 \times 18+30=66$ \\
6.0 & $2.5 \times 6.0=15.00$ & $32+30=94$ & $2 \times 32$ \\
\hline
\end{tabular}

* determined using a safety factor $\gamma=1.95$ and with account to tolerance of pipe assembly ( $3 \mathrm{~mm})$

** with account reserve for the gasket assembly $30 \mathrm{~mm}$ 
operation was demonstrated within two scopes. Firstly, the effort of the pipe subjected to traffic loads and mining influences (acting horizontal strains in the direction perpendicular to pipe's axis) was examined. For this purpose incremental-iterative numerical analysis (FEM) was used. Secondly, kinematic inputs simulating the influence of horizontal strains in the 2D model of pipe - soil were introduced. It has been shown that in the case of using lower class pipes and with high intensity of mining influences, the required safety factor $F$ is not achieved $(F<2.2)$. Additionally, the kinematic analysis of the pipe's joints was performed. It was shown that the joints used did not provide appropriate free movement of spigot in the socked. In the case of compressive horizontal strains pipe segments were pressed against each other which was the cause of joint damage.

\section{References}

[1] Hotloś, H., Mielcarzewicz, E. "Reliability conditions and assessment of proper functioning of water-pipe networks and sewer systems in areas affected by mining operations", Scientific Works of the Institute of Environmental Protection of the Technical University of Wrocław, Series: Monographs, Wrocław, Poland, 2011. (in Polish)

[2] Kwiatek, J. "Building structures on mining areas", GIG Publishing House, Katowice, Poland, 2007. (in Polish)

[3] Popiołek, E. "Protection of mining areas", AGH Publishing House, Krakow, Poland, 2009. (in Polish)

[4] Knothe, S. "Profile equation of the finally formed subsidence trough", Archives of Mining and Metallurgy, 1(1), pp. 22-37, 1953. (in Polish)

[5] Zieba, M. Kalisz, P. "Impact of Horizontal Soil Strains on Sewer Manholes and Pipelines within Mining Areas", IOP Conference Series: Materials Science and Engineering, 471(4), Article number: 042025, 2019.

https://doi.org/10.1088/1757-899X/471/4/042025

[6] Kalisz, P. "Impact of Mining Extraction on Above-Ground Pipelines", IOP Conference Series: Earth and Environmental Science, 362, Article number: 012152, 2019. https://doi.org/10.1088/1755-1315/362/1/012152

[7] Kalisz, P. Stec, K. "Oddziaływanie wstrząsów górniczych na gazociągi" (Impact of mining tremors on gas pipelines), Mining Review, 72(10), pp. 1-8, 2016. (in Polish)
The presented analysis of the causes of rigid stoneware pipe damage allows for the formulation of more general conclusions concerning the construction of pipelines in mining areas. For the safe functioning of pipelines in mining areas, apart from using pipes with an appropriate load capacity, it is essential to make the pipeline more flexible.

The effectiveness of such solutions depend on the proper use of the joints (e.g., by providing appropriate socked depths), flexible connection of pipes with manholes (e.g., in sewer systems) or other structures and careful execution of construction works. Moreover, in each case of laying pipelines in mining areas, the possibility of using flexible pipes (thermoplastic materials like PVC or PE) should be considered. Their interaction with the mining deformed subsoil is more effective than that of rigid pipes, despite the relatively low load-bearing capacity.

[8] Zhang, J., Xie, R. "Numerical Analysis of Mechanical Behavior of Buried Pipes in Subsidence Area Caused by Underground Mining", Journal of Pressure Vessel Technol,141(2), Article number: 021703, 2019.

https://oi.org/10.1115/1.4042711

[9] Kliszczewicz, B. "Numerical modelling of the impact of underground mining on pipelines. Part I - impact of continuous deformations", Architecture Civil Engineering Environment, 7(2), pp. 51-60, 2014.

[10] Kliszczewicz, B. "Numerical modelling of the impact of underground mining on pipelines, Pt. II - Impact of discontinuous deformations", Architecture Civil Engineering Environment, 7(3), pp. 43-48, 2014

[11] Kliszczewicz, B. "Zastosowanie modelu Hardening Soil Small w analizach numerycznych układu rura-grunt" (Application of the Hardening Soil Small model in numerical analyzes pipe-soil system), Construction and Environmental Engineering, 33(2/II/16), pp. 197-208, 2016. (in Polish) https://doi.org/10.7862/rb.2016.160

[12] Kalisz, P. "Impact of Mining Subsidence on Natural Gas Pipeline Failures", IOP Conference Series Materials Science and Engineering, 471, Article number: 042024, 2019. https://doi.org/10.1088/1757-899X/471/4/042024 